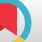

\title{
Investigating the Relationship Between Gender and Employment Status and Job Burnout in the Nursing Staff of the Armed Forces of Zahedan
}

\author{
Mahdi Khosravi Bijaem ${ }^{1}$ and Zahra Ghiasi (iD) ${ }^{2, *}$ \\ ${ }^{1}$ Department of Clinical Psychology, Zahedan Branch, Islamic Azad University, Zahedan, Iran \\ ${ }^{2}$ Department of Psychiatry, Zahedan University of Medical Sciences, Zahedan, Iran \\ "Corresponding author: Department of Psychiatry, Zahedan University of Medical Sciences, Zahedan, Iran. Tel: +98-5433420929, Email: linooshghiasi@gmail.com
}

Received 2018 October 02; Revised 2019 June 10; Accepted 2019 June 25.

\begin{abstract}
Background: Occupational burnout is a response to chronic stressors in work, and among nurses it can reduce the efficiency and quality of nursing care and increase hospital costs.

Objectives: This study aimed to examine the relationship between gender and employment status with occupational burnout in the nursing staff of armed forces of Zahedan.

Methods: In this descriptive correlation survey, 145 nursing staff were selected based on the Morgan's table and through random sampling from the nursing staff of the armed forces in hospitals of Nabi Akram and the Prophet of Azam in Zahedan, with 230 individuals in the community. A researcher-made questionnaire was used to collect demographic information. Another questionnaire for measuring job burnout was the Maslach and Jackson (1981) burnout inventory. In order to measure the reliability, 30 questionnaires were distributed to the respondents. After collecting the questionnaire and entering data, SPSS software, we calculate the Cronbach's alpha coefficient, which was 0.80 . Data were analyzed using chi-square $\left(\chi^{2}\right)$ with the significance level of $5 \%$ through SPSS software version 25.

Results: Data analysis showed that there was a significant relationship between gender and burnout (P value $=0.01)$. In this regard, burnout was higher in women. The relationship between the type of employment and job burnout was significant $(\mathrm{P}$ value $=0.01)$, and burnout was higher in the contractual frame.

Conclusions: Nurses are in the first line of health care provision. With regard to the results obtained, it is recommended that managers and authorities, especially for female and contracted nursing staff, place women in wards that are fitted with their mental capacity and refrain from placing them in wards with high levels of stress. On the other hand, by communicating with those who have a contractual employment status, they will be aware of their concerns and, by using other sources of support, could reduce the stress caused by uncertainty in the contractual situation.
\end{abstract}

Keywords: Gender, Employment Status, Job Burnout

\section{Background}

Job burnout syndrome, caused in response to the pressures of work, which is described as changing the behaviors and attitudes of staffs, becoming negative toward their job (1) and consisted of different dimensions.

Occupational burnout includes three dimensions of emotional exhaustion, depersonalization, and individual inefficacy (2). The exhaustion dimension was also described by Maslach and Leiter (3) as "wearing out, loss of energy, depletion, debilitation, and fatigue. The cynicism dimension was originally called depersonalization (given the nature of human services occupations), but was also described as negative or inappropriate attitudes towards clients, irritability, loss of idealism, and withdrawal. The inefficacy dimension was originally called reduced personal accomplishment, and was also described as reduced productivity or capability, low morale, and an inability to cope" (3).

Some researchers nowadays consider another component in their researches on burnout, which is called engagement.

At the beginning of the 21st century, investigators tried to expand the burnout concept by paying attention to the opposite concept that is positive and defined as "engage- 
ment". Engagement suggests a productive position in the job area. Some researchers understand engagement as an opposite concept of job burnout and like burnout consider three dimensions for that with positive aspects of that dimensions. Engagement concludes energetic state, powerful participation, and a sense of efficacy (4).

Today, the healthcare sector is one of the most important areas for sustainable development in human societies, due to its direct relationship with human health, including the staff of this field of nursing hospitals. Nurses are especially susceptible to job burnout because they are confronted with illness, pain, torment, and death of the recipients (5). The drop in the quality of patient care is one of the worst consequences of the burnout of nurses, when this happens, the patient is deprived of adequate care and his individuality and human rights are questioned (6).

In our country, $80 \%$ of health care workers are nurses. Nurses are in the first line of health care provision. A large number of studies show a high level of occupational stress and a lot of psychological and physiological breakdown in nurses, leading to job disconnection, employee conflicting, and severe displacement between wards, disturbances in health and disability, occupational vulnerability, and reduced quality of care, and ultimately, dissatisfaction and abdication of work (7).

Although burnout for 35 years been the subject of research in the field of social services, it is still one of the most comprehensive and the most common problems in this area (8). Today, job burnout is a problem in all health care settings. Based on available statistics, about $14 \%$ of nurses, at the end of the day, suffer from anorexia and exhaustion. Exhaustion has adverse effects on the physical and mental health of nurses, diminishes the effectiveness and quality of nursing care, and increases hospital costs (9)

Between the factors that contributed in generating a job burnout, socio demographic factors have a great portion. The most frequent factors in researches are: age, gender, work experience, marital status, parental status, managerial position, workplace, education, and additional employment (10-13).

According to a study conducted by Yavari et al. (5), among nurses in the psychiatric and specialist departments, the status of employment and service history were associated with burnout.

Khamisa et al. (14), did a study about job burnout in nurses. The results showed that there is a significant difference between the genders and the employment status of nurses with burnout. In women and individuals with contractual employment, burnout was more than others (14). Kilfedder et al. (15), also did a study on the burnout of nurses. The results showed that the rate of burnout in women is higher than men.
Klersy et al. (6), investigated job burnout in the nurses in dialysis ward. The results showed that the employment status in staff with contractual employment, not having a permanent job position, and being women have an effect on burnout.

The prevalence and effect of burnout on nurses in different work environments are not the same $(16,17)$. Regarding the work environment, it may be argued that nurses in the military system are among the most vulnerable nurses, which is due to the fact that work environments don't have enough flexibility.

Among the studies done in regards to the frequency and gender ratio of the nurses participating in the study, as well as the differences in these ratios in different wards of the hospital, and, of course, the difference in the stressfulness of the working environment (military environment and normal hospital environment) the results don't have enough integration and coherence to obtain an accurate understanding of job burnout and related demographic factors among nurses working in military environments. Furthermore, the necessary guidelines to address this problem is not available.

Occupational burnout is one of the major professional issues that imposes significant costs on organizations. Nursing is also known as a difficult profession that requires a lot of patience and tolerance. Nurses as one of the main rings of the healthcare chain, in addition to taking care of the patient in different areas of physical, mental, spiritual, etc., have the role of the father or mother, the spouse, the child, the student, etc. At the same time, these roles impose a lot of psychological stress on nurses, which can endanger their mental health and reduce their professional satisfaction and burnout.

Regarding the importance of burnout, several years of reports and statistics have been obtained in our country about the issue of burnout and other aspects related to them have been less expertly and professionally analyzed. The same studies and reports indicate that there has been no comprehensive study on burnout, especially in the nursing staff of the armed forces of Zahedan. Researchers, teachers, and students are required to conduct research in these areas. The subject of this research is valuable due to the importance of evaluating occupational burnout in order to find the factors that interfere in these areas in order to improve the quality and level of nursing staff effectiveness of Zahedan Armed Forces improvement and provide effective strategies for correct approach with nursing staff. Undoubtedly, the results of this research can be used by practitioners, planners, administrators, and other institutions. 


\section{Objectives}

Therefore, the main challenge of this research is whether there is a relationship between gender and employment status with burnout in the nursing staff of the Zahedan Armed Forces.

\section{Methods}

In this descriptive correlation survey, 145 nursing staff were selected based on Morgan's table, through random sampling from the nursing staff of the armed forces in hospitals of Nabi Akram and the Prophet of Azam in Zahedan, where the community had a population of 230 people.

For sampling, after the approval of the study, the researcher received the permission to distribute the questionnaire after receiving a letter from the Vice Chancellor of the Islamic Azad University of Zahedan Branch and presenting it to the authorities of Nabi Akram Hospital and the Prophet Azam of Zahedan. The researcher then, with permission from the hospital authorities, distributed the questionnaires among the nursing staff. After explaining the goals of their study and the units under study, the nursing staff was asked to study the questions and then respond. Before and after answering questions, all the units were appreciated. The completed questionnaires were collected on the same day from the units under study.

After coordination with the research unit of the hospital and obtaining the necessary permits for sampling, questionnaires were distributed without a name. All participants wrote informed consent. The data was analyzed confidentially by the researcher. The issue was approved at the 418 Committee's Center for Ethics.

A researcher-made form was used to collect information. This information form is designed by the researcher, and contains questions for demographic data and information needed for the purposes of this study.

Another questionnaire for measuring job burnout was Maslach and Jackson (1981) Burnout Inventory. The Maslach and Jackson Burnout Inventory questionnaire was created in 1981 and is a test to measure the amount of work-related emotional disturbances, a five-point Likert response format was used, as well as 22 questions and 3 dimensions. This questionnaire, for the first time was translated by Filian (1995) and the reliability and validity of the questionnaire was confirmed. The Cronbach's alpha coefficient was used and the alpha coefficient for the burnout questionnaire was 78\% (18). In our study, we added three questions for assessing the new dimension of "engagement".

For validity we use face validity, and five questionnaires were distributed among faculty members and experts in sociology and psychology. The validity of the questionnaire was confirmed by their viewpoints.

For approving content validity, we use the Content Validity ratio and Content Validity index. Content Validity ratio: Based on the panel point of view to ensure that item for measurement structures are designed in the best way, a three-part Likert criterion for each item is essential. The CVR, according to Lavasheh's table, was between $99 \%$ and 1 for each of the questions.

Content Validity index: To ensure that the item for measuring the structures is designed in the best way, 3 criteria with 4 part Likert criterion for each item is essential: (1) simplicity, (2) related or dedicated, and (3) transparency and clarity.

CVI for each question was more than 0.7. Therefore, the questionnaire has an appropriate validity.

In order to measure the reliability, 30 questionnaires were provided to the respondents. After collecting the questionnaire and entering data by SPSS software, Cronbach's alpha coefficient for the burnout questionnaire was 0.80 . The reliability of the questionnaire was confirmed.

Of course, the validity and reliability of this questionnaire with 25 questions, was previously approved by Ghahramani et al. (19).

After collecting the questionnaire and entering data, Data were analyzed using descriptive statistics, and chisquare $\left(\chi^{2}\right)$ with the significance level of $5 \%$ through SPSS software version 25 .

\section{Results}

In this study, of the 145 participants who completed the questionnaires, 96 (66.2\%) were female and 49 (33.8\%) were male. Regarding employment status, 86 (59.3\%) had official hiring and 59 (40.7\%) had contractual status.

Since the frequency of response in some categories was 0 , we integrate the two end-point of the Likert spectrum as "high" and the two initial points of the Likert spectrum as "low".

Regarding relationship between gender and job burnout, chi-square test was used and the outcomes are presented in Table 1.

The results of Table 1 show that there was a significant relationship between gender and burnout ( $P$ value $=0.01$ ) In this regard, burnout was higher in women.

Also, in the dimensions of burnout, emotional exhaustion, depersonalization, inefficacy, and engagement, the $\mathrm{P}$ value is equal to $0.02,0.01,0.02,0.02$, respectively. Therefore, the relationship between gender and burnout dimensions was significant, and job burnout and its dimensions are higher in women. 


\begin{tabular}{|c|c|c|c|c|c|c|c|c|c|}
\hline & \multicolumn{4}{|c|}{ Male } & \multicolumn{4}{|c|}{ Female } & \multirow{2}{*}{ PValue } \\
\hline & Low & Moderate & High & Total & Low & Moderate & High & Total & \\
\hline Burnout & $7(13.3)$ & $29(58.4)$ & $13(28.3)$ & $49(100)$ & $3(2.7)$ & $68(70.2)$ & $25(27.1)$ & $96(100)$ & 0.01 \\
\hline Emotional exhaustion & $4(8.2)$ & $37(75.5)$ & $8(16.3)$ & $49(100)$ & $13(13.5)$ & $69(71.9)$ & $14(14.6)$ & $96(100)$ & 0.02 \\
\hline Depersonalization & $0(0.00)$ & $37(75.5)$ & $12(24.5)$ & $49(100)$ & $3(3.1)$ & $18(18.8)$ & $75(78.1)$ & $96(100)$ & 0.01 \\
\hline Inefficacy & $10(20.8)$ & $29(58.4)$ & $10(20.8)$ & $49(100)$ & $23(24.08)$ & $67(70)$ & $5(5.02)$ & $96(100)$ & 0.02 \\
\hline Engagement & $10(20.4)$ & $17(32.7)$ & $22(46.9)$ & $49(100)$ & $21(21.9)$ & $48(50)$ & $27(28.1)$ & $96(100)$ & 0.02 \\
\hline
\end{tabular}

${ }^{a}$ Values are expressed as No. (\%).

Regarding the relationship between the type of employment and burnout and its dimensions, the results are presented in Table 2.

The results of Table 2 show that the relationship between the type of employment and job burnout was significant $(\mathrm{P}$ value $=0.01$ ). In this regard, job burnout was higher in the contractual status.

Also, in the dimensions of burnout, emotional exhaustion, depersonalization, inefficiency, and engagement, $\mathrm{P}$ value $=0.01,0.01,0.01,0.01$, respectively. Therefore, there was a significant relationship between employment type and burnout dimensions, however, emotional exhaustion, depersonalization, inefficiency, and engagement in the contractual frame are higher.

\section{Discussion}

There is a significant relationship between gender and job burnout and its dimensions in the nursing staff of Zahedan Armed Forces, and job burnout and its dimensions are higher in women. These results are consistent with the findings of Khamisa et al. (14), Kilfedder et al. (15), Li et al. (20), Yao et al. (21), Ohue et al. (22), Lasebikan and Oyetunde (23), and Klersy et al. (6), which showed that burnout and its dimensions are higher in women.

Therefore, it is understood that women are more emotionally sensitive and because men imagine their job as the provider of all the costs of their lives and family, they have less social and psychological pressure than women. In addition, this can be due to women's personality traits and more compliance, which is also more necessary in nursing professions.

The results also showed that the relationship between employment type and job burnout and its dimensions is significant in the nursing staff of Zahedan Armed Forces, in which the burnout rate and its dimensions are higher in the contractual nursing staff. These results are consistent with the findings of, Khamisa et al. (14), and Klersy et al. (6). Interestingly, the results of this research are contradictory with the findings of Golbasi et al. (24), regarding job satisfaction of nurses with contractual condi- tions. Of course, the researchers themselves mention that the higher level of satisfaction in contracted nurses is related to the amount of their challenge and their attempt to obtain a permanent status, in which case the apparent disagreement with the results is justifiable (24).

The reason for this can be the fact that the personnel with contracted employment feels insecure about her work and should try more than other personnel who have permanent status until obtain permanent status. On the other hand, official personnel have made the decision to stay in the organization because of their investment, the cost of leaving a job or the lack of other job opportunities or personal priorities and needs. In other words, they are the official personnel in the organization, because it is necessary for them to remain in the organization. Indeed, it can be said that employees in these organizations are left behind in the organization due to the investment that the organization has for them and the years and perspectives they have in the organization. In addition, if they leave the organization, they will lose their privileges, despite the fact that they are bored. Therefore, they justify their exhaustion mentally and seems that they are not bored and themselves also believe this justification. However, for individuals who have contractual status and don't have this justification, may be bored earlier and higher than persons who have official status $(25,26)$.

The findings of this study have great importance, because this study is one of the few studies in military work environment, and has examined the relationship between demographic characteristics and burnout in the highrisk group of armed forces nurses in Iran. On the other hand, knowing the factors that contribute to this problem will help administrators to prevent and resolve this phenomenon.

Overall, the present study suggests that managers and authorities, especially for female and contracted nursing staff, place women in wards that are fitted with their mental capacity and refrain from placing them in wards with high levels of stress. On the other hand, by communicating with those who have a contractual employment status, they will be aware of their concerns and, by using other 


\begin{tabular}{|c|c|c|c|c|c|c|c|c|c|}
\hline & \multicolumn{4}{|c|}{ Contractual } & \multicolumn{4}{|c|}{ official } & \multirow{2}{*}{ P Value } \\
\hline & High & Moderate & Low & Total & High & Moderate & Low & Total & \\
\hline Burnout & $16(32.2)$ & $30(61.0)$ & $3(6.8)$ & $49(100)$ & $18(19.4)$ & $66(67.1)$ & $13(13.5)$ & $96(100)$ & 0.01 \\
\hline Emotional exhaustion & $10(20.2)$ & $35(71.2)$ & $4(8.6)$ & $49(100)$ & $7(8.2)$ & $62(64.4)$ & $26(27.4)$ & $96(100)$ & 0.01 \\
\hline Depersonalization & $39(79.7)$ & $8(16.9)$ & $2(3.4)$ & $49(100)$ & $17(19.4)$ & $77(80.5)$ & $2(2.1)$ & $96(100)$ & 0.01 \\
\hline Inefficacy & $12(25.4)$ & $30(60.8)$ & $7(13.7)$ & $49(100)$ & $10(11.2)$ & $52(54.1)$ & $33(34.7)$ & $96(100)$ & 0.01 \\
\hline Engagement & $14(28.8)$ & $30(60.8)$ & $10(20.3)$ & $49(100)$ & $18(18.4)$ & $37(39.5)$ & $41(42.1)$ & $96(100)$ & 0.01 \\
\hline
\end{tabular}

${ }^{a}$ Values are expressed as No. (\%).

sources of support, could reduce the stress caused by uncertainty in the contractual situation.

\section{Acknowledgments}

This article is the result of a Master's thesis submitted to the Islamic Azad University of Zahedan Branch in the field of clinical psychology. The authors sincerely express their gratitude to the staff (administrative and medical staff) of the Prophet of Islam (PBUH) Hospital and Nabi Akram (pbuh) of Zahedan and the nurses participating in this project. We would like to thank the Research Council of the Clinical Psychology Department who approved this proposal.

\section{Footnotes}

Authors' Contribution: Study concept and design: Zahra Ghiasi and Mahdi Khosravi Bijaem. Acquisition of data: Mahdi Khosravi Bijaem. Analysis and interpretation of data: Mahdi Khosravi Bijaem. Drafting of the manuscript: Zahra Ghiasi. Statistical analysis: Mahdi Khosravi Bijaem.

Conflict of Interests: The authors declare no conflict of interests.

Ethical Approval: This article is the result of a master's thesis submitted to the Islamic Azad University of Zahedan Branch in the field of clinical psychology with the moral code of IR.ZAUMS.REC.1397.216.

Funding/Support: This study was conducted without financial support.

\section{References}

1. Li A, Early SF, Mahrer NE, Klaristenfeld JL, Gold JI. Group cohesion and organizational commitment: Protective factors for nurse residents' job satisfaction, compassion fatigue, compassion satisfaction, and burnout. J Prof Nurs. 2014;30(1):89-99. doi: 10.1016/j.profnurs.2013.04.004. [PubMed: 24503320].

2. Emold C, Schneider N, Meller I, Yagil Y. Communication skills, working environment and burnout among oncology nurses. Eur J Oncol Nurs. 2011;15(4):358-63. doi: 10.1016/j.ejon.2010.08.001. [PubMed: 20863757].
3. Maslach C, Leiter MP. Understanding the burnout experience: Recent research and its implications for psychiatry. World Psychiatry. 2016;15(2):103-11. doi: 10.1002/wps.20311. [PubMed: 27265691]. [PubMed Central: PMC4911781].

4. Maslach C, Leiter MP. Burnout and engagement in the workplace: A contextual analysis. Adv Motiv Achiev. 1999;11:275-302.

5. Yavari M, Shamsaei F, Yazdanbakhsh K. [Comparison of burnout and mental health of nurses working in psychiatric and specialist departments (ICUs)]. Q J Nurs Manage. 2014;3(1):55-65. Persian.

6. Klersy C, Callegari A, Martinelli V, Vizzardi V, Navino C, Malberti F, et al. Burnout in health care providers of dialysis service in Northern Italya multicentre study. Nephrol Dial Transplant. 2007;22(8):2283-90. doi: 10.1093/ndt/gfm111. [PubMed: 17442744].

7. Taqipour K. [A survey on the relationship between job stress and job burnout in Shahrekord Forensic Medical Staff]. Psychol Educ Sci. 2016;3(14):57-70. Persian.

8. Nowacka A, Piskorz A, Wolfshaut-Wolak R, Piatek J, Gniadek A. Selected socio-demographic and occupational factors of burnout syndrome in nurses employed in medical facilities in Malopolskapreliminary results. Int J Environ Res Public Health. 2018;15(10). doi: 10.3390/ijerph15102083. [PubMed: 30248946]. [PubMed Central: PMC6210706].

9. Soleimani R, Shokrgozar S, Kianmehr S, Fallahi M, Pakdaman M. Comparison of mental health and burn out in Medical Staff of Rasht Shafa and Heshmat Hospitals. Res Med Educ. 2016;7(4):20-30. doi: 10.18869/acadpub.rme.7.4.20.

10. Ifeagwazi FCM. The Influence of marital status on self-report of symptoms of psychological burnout among nurses. Omega. 2016;52(4):359-73. doi: 10.2190/dnbr-8e28-jxtm-meaw.

11. Tunc T, Kutanis RO. Role conflict, role ambiguity, and burnout in nurses and physicians at a university hospital in Turkey. Nurs Health Sci. 2009;11(4):410-6. doi: 10.1111/j.1442-2018.2009.00475.x. [PubMed: 19909450].

12. Stavrolula L, Aditya J. Health impact of psychosocial hazards at work: An overview. Geneva, Switzerland: World Health Organization; 2010.

13. Maslach C, Jackson SE, Leiter MP, Schaufeli WB, Schwab RL. Maslach burnout inventory. Palo Alto, CA: Consulting Psychologists Press; 1986.

14. Khamisa N, Oldenburg B, Peltzer K, Ilic D. Work related stress, burnout, job satisfaction and general health of nurses. Int J Environ Res Public Health. 2015;12(1):652-66. doi: 10.3390/ijerph120100652. [PubMed: 25588157]. [PubMed Central: PMC4306884].

15. Kilfedder CJ, Power KG, Wells TJ. Burnout in psychiatric nursing. J Adv Nurs. 2001;34(3):383-96. doi: 10.1046/j.1365-2648.2001.01769.x. [PubMed: 11328444].

16. Kashani M, Eliasson A, Chrosniak L, Vernalis M. Taking aim at nurse stress: A call to action. Mil Med. 2010;175(2):96-100. doi: 10.7205/milmed-d-09-00092. [PubMed: 20180478].

17. Lang GM, Patrician P, Steele N. Comparison of nurse burnout across army hospital practice environments. J Nurs Scholarsh. 2012;44(3):27483. doi: 10.1111/j.1547-5069.2012.01462.x. [PubMed: 22882620].

18. Filian E. [Evaluation of burnout and its relationship with confronting methods among nurses working at educational hospitals]. Tehran: Tehran Teacher Training University; 1991. Persian. 
19. Ghahramani M, Arastehnazar Z, Meemar MA. [Effect of locus control on burnout in instructors of Iranian governments literal movement]. Qua J Car Organiz Counsel. 2011;4(4):291-7. Persian.

20. Li X, Guan L, Chang H, Zhang B. Core self-evaluation and burnout among Nurses: The mediating role of coping styles. PLoS One. 2014;9(12). e115799. doi: 10.1371/journal.pone.0115799. [PubMed: 25541990]. [PubMed Central: PMC4277418].

21. Yao Y, Yao W, Wang W, Li H, Lan Y. Investigation of risk factors of psychological acceptance and burnout syndrome among nurses in China. Int J Nurs Pract. 2013;19(5):530-8. doi: 10.1111/ijn.12103. [PubMed: 24093745].

22. Ohue T, Moriyama M, Nakaya T. Examination of a cognitive model of stress, burnout, and intention to resign for Japanese nurses. Jpn J Nurs Sci. 2011;8(1):76-86. doi: 10.1111/j.1742-7924.2010.00161.x. [PubMed: 21615700].

23. Lasebikan VO, Oyetunde MO. Burnout among nurses in a Nigerian General Hospital: Prevalence and associated factors. ISRN
Nurs. 2012;2012:402157. doi: 10.5402/2012/402157. [PubMed: 22619733] [PubMed Central: PMC3350958].

24. Golbasi Z, Kelleci M, Dogan S. Relationships between coping strategies, individual characteristics and job satisfaction in a sample of hospital nurses: Cross-sectional questionnaire survey. Int J Nurs Stud. 2008;45(12):1800-6. doi: 10.1016/j.ijnurstu.2008.06.009. [PubMed: 18703192].

25. Shang J, You L, Ma C, Altares D, Sloane DM, Aiken LH. Nurse employment contracts in Chinese hospitals: Impact of inequitable benefit structures on nurse and patient satisfaction. Hum Resour Health. 2014;12:1. doi: 10.1186/1478-4491-12-1. [PubMed: 24418223]. [PubMed Central: PMC3896777].

26. Virtanen M, Kivimaki M, Elovainio M, Vahtera J, Ferrie JE. From insecure to secure employment: Changes in work, health, health related behaviours, and sickness absence. Occup Environ Med. 2003;60(12):948-53. doi: 10.1136/oem.60.12.948. [PubMed: 14634187]. [PubMed Central: PMC1740437]. 